\title{
ESCÚCHAME CON TU CUERPO ENTERO: ANTIOCULARCENTRISMO, CRISIS DE LA PALABRA Y SINESTESIA EN CLARICE LISPECTOR
}

LISTEN WITH YOUR WHOLE BODY: ANTIOCULARCENTRISM, CRISIS OF THE WORD AND

SYNESTHESIA IN CLARICE LISPECTOR

Renata Pontes

Pontificia Universidad Católica de Chile Santiago - Chile

Temple University Filadélfia - Estados Unidos

\begin{abstract}
This analysis addresses two key texts by Clarice Lispector, The Stream of Life (Água viva, 1973) and "Love" ("Amor" - the second story in Laços de família, 1960) avoiding the oft-repeated intimate and metalinguistic classifications of the writer's work and suggesting an opening to contradiction, latency and inconclusiveness as writing and interpretation procedures. Instead of a categorical reading from the perspective of a specific genre, this paper proposes, in line with the author's indications in both writings, a theoretical approach to Heniz von Foerster's observation system, the antiocularcentrism analyzed by Martin Jay and the notion of crisis of the word in Michel Foucault. As an alternative reading, narration, experimentation and synesthesia are indicated as possible approximations to both texts. Finally, the relationship between literature and life in Lispector's oeuvre is highlighted and it is observed how language issues point to political positions that radically transform the act of reading and anticipate its possible consequences, far beyond the literary text.
\end{abstract}

Keywords: Contradiction, latency, anticularcentrism, synesthesia.

\section{Resumen}

Este análisis aborda dos textos fundamentales de Clarice Lispector, Água viva (1973) y "Amor" - segundo cuento de Laços de família (1960) evitando las reiteradas clasificaciones intimista e metalingüística de la obra de la escritora y sugiriendo una apertura a la contradicción, latencia e inconclusión como procedimiento de escritura y de interpretación. En lugar de una lectura categórica desde un género específico,

\section{Resumo}

Esta análise aborda dois textos fundamentais de Clarice Lispector, Água viva (1973) e "Amor" - segundo conto de Laços de família (1960) evitando as reiteradas classificações intimista e metalinguística da obra da escritora e sugerindo uma abertura à contradição, latência e inconclusão como procedimentos de escritura e de interpretação. Em lugar de uma leitura categórica desde um gênero específico, 
es propuesta, en correspondencia con las indicaciones de la autora en ambos escritos, una aproximación teórica al sistema de observación de Heinz von Foerster, al antiocularcentrismo analizado por Martin Jay y la noción de crisis de la palabra en Michel Foucault. Como alternativa de lectura la narración, la experimentación y la sinestesia son indicadas como aproximaciones posibles a ambos textos. Finalmente, la relación entre literatura y vida en la escritura de Lispector es destacada y se observa como los problemas de lenguaje apuntan a posiciones políticas que transforman radicalmente el acto de lectura y anticipan las posibles consecuencias, más allá del texto literario.

Palabras claves: Contradicción, latencia, antiocularcentrismo, sinestesia. se propóe, em correspondência com as indicaçōes da autora em ambos escritos, uma aproximaçáo teórica ao sistema de observação de Heinz von Foerster, ao antiocularcentrismo analizado por Martin Jay e a noção de crise da palavra em Michel Foucault. Como alternativa de leitura, se indica a narração, a experimentação e a sinestesia como aproximaçóes possíveis a ambos os textos. Finalmente, destacase a relaçáo entre literatura e vida na escrita de Lispector e se observa como os problemas de linguagem apontam para posicionamentos políticos que transformam radicalmente o ato de leitura e antecipam suas possíveis consequências, muito além do texto literário.

Palavras-chave: Contradição, latência, anticularcentrismo, sinestesia.

Quando o amor é grande demais torna-se inútil: já não é mais aplicável, e nem a pessoa amada tem a capacidade de receber tanto. Fico perplexa como uma criança ao notar que mesmo no amor tem-se que ter bom senso e senso de medida. $A h$, a vida dos sentimentos é extremamente burguesa.

Clarice Lispector, Jornal do Brasil, 1968

Durante la entrevista concedida para la TV Cultura de Brasil en 1977, Clarice Lispector afirma, sobre las diversas formas de leer su obra: "Ou toca ou não toca. Quer dizer, suponho que me entender não é uma questão de inteligência e sim de sentir, de entrar em contato" (parte 5/4'11"). Categórica, refuerza una característica que se convirtió en una marca de su escritura. La crudeza de expresión se manifiesta a través de dos procedimientos aparentemente contradictorios: el uso de un vocabulario conocido - "eu escrevo simples, eu não enfeito" (parte 5/7'15") - y la presencia de situaciones, por decirlo de algún modo, "insólitas". El periodista Julio Lerner, realizador de 
la entrevista, capta el resultado: "las cosas simples, en los días actuales, son comprendidas de forma complicada” (parte 5/7'10"). Al mismo tiempo, es posible considerar otros problemas (y no soluciones) de la paradoja de una escritura extraña construida de forma simple. La literatura es cuestión de vida, a tal punto, que Clarice Lispector llega a asegurar, en la misma conversación: "eu acho que quando não escrevo estou morta" (parte 2/4’27"). En el mismo sentido, el involucramiento de la escritora con sus personajes es notorio y se concibe como recurso narrativo. Sobre este aspecto, durante esta (peculiar) aparición pública, Lispector explica uno de sus trabajos preferidos como "una cosa" que escribió sobre un criminal llamado "mineirinho", muerto con 13 balazos por la policía. De acuerdo con su relato, el personaje era devoto de São Jorge y estaba comprometido. El impacto afectivo que le provoca el asesinato -inspirado en una noticia de la época- se expresa en el proceso de composición del texto, cuando la escritora admite un acercamiento visceral al personaje: "Qualquer coisa assim como o primeiro tiro me espanta; o segundo tiro num sei quê; o terceiro tiro, coisa; o décimo segundo me atinge; o décimo terceiro sou eu. Eu era, me transformei no mineirinho, massacrado pela polícia. Qualquer que tivesse sido o crime dele uma bala bastava, o resto era vontade de matar. Era prepotência" (parte 2/7'14", énfasis nuestro).

Sobre sus escritos favoritos, Clarice Lispector también menciona el cuento "O ovo e a galinha"', el único texto autoral que considera hermético: "é um mistério para mim" (parte 2/6'25"). El comentario alude a un significativo movimiento de su escritura, la evocación de un lado oblicuo de la vida, convicción que se hace evidente en Água viva ${ }^{2}$ :

Como vês és-me impossivel aprofundar e apossar-me da vida, ela é aérea, é o meu leve hálito. Mas bem sei o que quero aqui: quero o inconcluso. Quero a profunda desordem orgânica que no entanto dá a pressentir uma ordem subjacente. A grande potência da potencialidade. Estas minhas frases balbuciadas são feitas na hora mesma em que estâo sendo escritas e crepitam de tão novas e ainda verdes. Elas são o já. Quero a experiência de uma falta de construção. Embora este meu texto seja todo atravessado de ponta a ponta por um frágil fio condutor -qual? o do mergulho na matéria da palavra? o da paixão? Fio luxurioso, sopro que aquece o decorrer das sílabas. A vida mal e mal me escapa embora me venha a certeza de que a vida é outra e tem um estilo oculto. (1998a, p. 7, énfasis nuestro)

Consciente de la calidad etérea de la vida, la narradora de Água viva desea acercarse a un orden orgánico que no deja de ser subyacente. Desde ya

1 Cuento publicado en Legiäo estrangeira (1964) y Felicidade clandestina (1971).

2 Todas las citas se refieren a esta edición. 
se percibe la imbricación entre literatura y vida. Las sílabas sopladas de su escritura-leves como la existencia misma- son imprecisas, balbuceadas. Son palabras verdes y nuevas -luego dirá: intocadas. Son hechas en el instante en que se escriben. En estos desplazamientos, el propósito de la palabra se enlaza con la finalidad del libro y con la búsqueda más íntima del personaje, como se expresa en la declaración inicial de la pintora-narradora: "Eu te digo: estou tentando captar a quarta dimensão do instante-já que de tão fugidio não é mais porque agora tornou-se um novo instante-já que também não é mais" (2). Sin embargo, ajeno a cualquier voluntad el sentimiento de defraude provocado por la incomprensión se manifiesta reiteradamente y, en muchos fragmentos de Água viva, resta cualquier poder de significación a la palabra:

Eis que de repente vejo que há muito não estou entendendo. $\mathrm{O}$ gume de minha faca está ficando cego? Parece-me que o mais provável é que náo entendo porque o que vejo agora é difícil: estou entrando sorrateiramente em contato com uma realidade nova para mim que ainda não tem pensamentos correspondentes e muito menos ainda alguma palavra que a signifique: é uma sensação atrás do pensamento. (p. 32, énfasis nuestro)

Siendo así, ¿`ómo abordar una escritura que pretende esbozar lo que el pensamiento no corresponde y la palabra no significa? En Água viva se sugiere la entrega a la sensación. Además, se reivindica el saber intuitivo y se evoca el lenguaje sonoro, como en este ilustrativo fragmento: "Ouve-me, ouve o meu silêncio. O que falo nunca é o que falo e sim outra coisa. Quando digo "águas abundantes" estou falando da força de corpo nas águas do mundo. Capta essa outra coisa de que na verdade falo porque eu mesma náo posso. Lê a energia que está no meu silêncio. Ah tenho medo do Deus e do seu silêncio" (p. 19, énfasis nuestro). Como se revela, la experiencia con el texto implica aceptar su alto grado de latencia. No obstante, la narradora, más allá de sus imposibilidades, deposita gran confianza en las capacidades del lectorreceptor. Porque el papel del escritor no es entender o explicar lo que escribe, sino tirar el anzuelo: "Então escrever é o modo de quem tem a palavra como isca: a palavra pescando o que não é palavra. Quando essa não-palavra -a entrelinha- morde a isca, alguma coisa se escreveu. Uma vez que se pescou a entrelinha, poder-se-ia com alívio jogar a palavra fora. Mas aí cessa a analogia: a não-palavra, ao morder a isca, incorporou-a o que salva então é escrever distraidamente" (13). Al mismo tiempo, escribir despreocupada de significar guarda íntima relación con la actitud del personaje hacia la vida: "Não quero ter a terrível limitação de quem vive apenas do que é passível de fazer sentido. Eu não: quero é uma verdade inventada" (13). Por todo esto, en Água viva la literatura se delinea como supervivencia y la liberación de la palabra, como emancipación desinteresada: "Luto por conquistar mais profundamente a 
minha liberdade de sensações e pensamentos, sem nenhum sentido utilitário: sou sozinha, eu e minha liberdade" (14).

Como se percibe, la meta-reflexión es llevada al extremo -no se sabe, no se entiende y no hay pensamientos ni palabras que signifiquen- para invitar los receptores a una experiencia totalmente nueva. Sin embargo, la explicación metalingüística e intimista -que prevalece en la crítica brasileña- no limita las posibilidades de interpretación. En búsqueda de nuevos acercamientos, Eleonora Pedrón, en "Clarice Lispector: una lectura a partir del desconcierto", plantea una pregunta básica, empero fundamental: ¿Cómo adentrar la textualidad de su obra? En este esfuerzo, enumera la extensa producción y afirma:

Cada uno de estos textos repite paradigmáticamente una misma atmosfera de riesgo, una misma sensación de vacío que organiza la ficción y, al mismo tiempo, determina la relación entre el lector y el texto: descentramiento del personaje, impotencia del narrador, dispersión del referente, displacer del receptor por las expectativas continuamente generadas para luego ser defraudadas. (1995, p. 212)

De acuerdo con Pedrón, la obra de la escritora brasileña se sustenta en una especie de inconclusión prolongada que escapa a las tentativas de definición. En consonancia con esta hipótesis, este análisis se desprende de la concepción de un género o estilo dominante y acepta, como punto de partida, la naturalización de la paradoja. Este camino incierto parece ser el único posible frente a una escritora que niega "la secura" de las palabras como medio de expresión, sugiere una aproximación táctil al acto de leer, y propone la intuición como medio privilegiado de conocimiento. Con estos gestos, Clarice Lispector evita la omnipotencia de la representación del lenguaje fundamentada en la supremacía de la "visión/visualidad"3 - y elude la lógica racional como principal recurso del entendimiento. Sin embargo, sobre la aproximación crítica, ¿no conlleva una contradicción inherente el parafraseo de una escritura deliberadamente borrosa e inconclusa? Considerando los límites

\footnotetext{
3 En Ojos abatidos. La denigración de la visión en el pensamiento francés del siglo XX, Martin Jay -apoyado en constataciones de la ciencia natural contemporánea-asegura una relación privilegiada entre el lenguaje y "la vista", a diferencia de los otros sentidos. Esta defensa afirma la permeabilidad de los límites entre los componentes "natural" y "cultural" en lo que se denomina como visión: "Aunque la percepción está íntimamente vinculada con el lenguaje como un fenómeno genérico, es patente que los pueblos diferentes hablan lenguas diferentes. Como resultado, la universalidad de la experiencia visual no puede asumirse de manera automática, por cuanto esa experiencia está en parte mediada lingüísticamente. En consecuencia, la propia ciencia natural apunta la posibilidad de variables culturales, al menos en cierto grado. En otras palabras, eso implica el inevitable enmarańamiento de la visión y de lo que se ha denominado "visualidad" (las distintas manifestaciones históricas de la experiencia visual en todas sus posibles modalidades). La observación, por decirlo de otra forma, exige observar las reglas culturales tácitas de los diferentes regímenes escópicos". (2007, p. 16).
} 
de esta interpretación, el esfuerzo será aprovechar positivamente las paradojas y latencias que acompañan la literatura de Clarice Lispector. Evocando algunas nociones de Heinz von Foerster -recuperadas por Niklas Luhmann- se propone un acercamiento al complejo "sistema de observación". En esta perspectiva, la primera pregunta se refiere al punto ciego de este ejercicio: ¿Cuál es el lado (y no el otro) que se desea indicar? La intención -lejos de la embestida de una lectura cerrada- expresa la voluntad de amalgamar el acto de lectura con las repetidas sugerencias de Água viva y "Amor”, el segundo cuento de Laços de familia, que también será objeto de este análisis. Escuchando con el cuerpo entero y aspirando a sentir y captar la energía de los silencios, la narración ${ }^{4}$, el empirismo y la sinestesia ${ }^{5}$ se configuran como aproximaciones posibles.

La actitud crítica también indica una resistencia a las lecturas recalcadas, metaforizando la consistencia escurridiza de los escritos. Sin embargo: ¿Cuál es el límite del discurso? ¿En qué marco se circunscribe? Asumiendo lo obvio, la palabra es la condición de posibilidad de los textos literario y crítico. Esto no impide, por otro lado, una primera distinción en consonancia con la "cibernética de segundo orden"6: no aplicar valores lógicos

4 En "Sobre algunos temas en Baudelaire", Walter Benjamin relaciona la atrofia de la experiencia a la afirmación y prestigio de la información. En contrapartida, en la narración, una de las formas más antiguas de comunicación: "Lo que importa no es transmitir el puro en sí de lo sucedido (que así lo hace la información); (la narración) se sumerge en la vida del que relata para participarla como experiencia a los que oyen. Por eso lleva inherente la huella del narrador, igual que el plato de barro lleva la huella de la mano del alfarero" (1972, p. 127).

5 En "Blindness as Metaphor", Naomi Schor amplía el sentido del término sinestesia: "The world of sensory deprivation is ruled by another tropological system, that commanded by synesthesia and favored by so-called visionary poets such as Victor Hugo, Charles Baudelaire, and Arthur Rimbaud; synesthesia is the trope of liminal sensory states that arise not when the senses are overloaded-etymologically synesthesia is from the Greek sunaisthêsis meaning "simultaneous perception"-but rather thrown out of balance: in synesthesia vision is handed over to speech, smell is made tactile, and motion is translated into sound. In the realm of deficient senses, the crossing of sensory borders is an effect not of plenitude, but of lack: absent one sense, another comes to substitute for it, to supplement its absence rather than to add to its presence" (1999, p. 100). En esta perspectiva, es posible indicar que, en Água viva y "Amor", aparece la simultaneidad de los sentidos y también la expansión de la sinestesia a una experiencia sensitiva que busca el equilibrio y la supresión de una falta. No obstante, a diferencia de los casos analizados por Schor, no se trata, en la escritura de Lispector, de pensar esta aplicabilidad en el reino de la deficiencia de los sentidos, aunque en "Amor" la presencia de un ciego desencadene la historia. En Água viva la proposición es metalingüística y permite pensar la evocación sinestésica como intento de superación de la debilidad de la palabra. La convivencia de los sentidos aparece como analogía a la imbricación entre los artes, con privilegio del lenguaje musical. En "Amor", la protagonista Ana observa la diferencia y experimenta un mundo nuevo en que prevalece la complementariedad de los sentidos. La aparente armonía de su destino de mujer puede ser entendida como una ceguera metafórica.

6 En “¿Cómo se pueden observar estructuras latentes?” Luhmann describe el siguiente contexto: "Heinz von Foerster nos invita a continuar. Su fórmula mágica no se denomina anamnesis, se denomina observing systems. O también, con otro giro de la misma (?) idea: surviving failures. La fórmula señala y oculta de manera hábil lo que suele denominarse también cibernética de segundo orden o cibernética de la observación de observadores" (1998, p. 61). Lo esencial de la aplicación del concepto es que no se resume al reconocimiento de la pluralidad de sujetos, ni al descubrimiento del constituyente de su ser-constituido o a la consecuente aceptación de una descripción "policontextual" del mundo. Buscando 
adicionales. Desde esta máxima, la literatura de Lispector y los presupuestos teóricos del sistema de observación se entrecruzan en el desacuerdo esencial con una descripción del mundo unísona y accesible a todos los observadores. En el caso de la ficción, esta posición se expresa en afirmaciones como esta, en Água viva: "Ocorreu-me de repente que não é preciso ter ordem para viver. Não há padrão a seguir e nem há o próprio padrão: nasço" (25). En la reflexión de Luhmann, se manifiesta en una extensa explicación sobre la cibernética de segundo orden:

El cambio epistemológico introducido así se hace claro si se explica que en realidad se basa en una teoría de la cognición, pero que esa línea de indagación ya no persigue el propósito de confeccionar una descripción del mundo accesible a todos los observadores. Lo que se presupuso como mundo se retira a lo inobservable de un unmarked state (Spencer Brown). Sólo se puede observar con el auxilio de un corte, de un límite, de una muesca, que se puede observar pero no "suprimir" sin regresar a lo inobservable. Esto es aceptado ampliamente hoy, por lo menos fuera de la teoría académica del conocimiento. Sin embargo, las consecuencias llegan mucho más allá. La distinción ontológica ser/no ser pierde su primacía teórica y la forma binaria de la lógica clásica su primacía metodológica. (LUHMANN, 1998, p. 68-69)

En consonancia con esta perspectiva, en lo metodológico se concede privilegio al sentido abstracto de la observación. Si, como sustenta Luhmann, este camino teórico permite preservar la latencia de toda interpretación y evitar las ratificaciones sistémicas; en la escritura de Clarice Lispector, esta indicación ayuda a observar, con especial interés, la oblicuidad narrativa. Por otro lado, el sentido de nuestra distinción/indicación conecta los movimientos del lenguaje de Água viva y "Amor" con el trastrueque epistemológico, lo que implica asumir un posicionamiento frente a los fundamentos culturales hegemónicos. Desde esta perspectiva, nuestra lectura sesgada percibe en estos textos actos de resistencia al paquete de antónimos que define el perfil intelectual del liberalismo. Además, identificamos en estos escritos una clara oposición a la pretensa "unidad de lo distinguido" que, como explica Luhmann, no libra el conocimiento hegemónico de la paradoja sino que le obliga a una solución creativa de la misma (1998, p. 68-69). Estas posiciones políticas ganan lugar en las inflexiones de la palabra escrita. Distinguiendo e indicando caminos posibles, evitar la unicidad cognitiva también implica experimentar desde otros lugares. Siendo así, más allá del lenguaje verbal, consideramos la puesta en escena del cuerpo como lenguaje, en los términos

una mejor definición de la noción, Luhmann sugiere las preguntas: ¿Cómo se sigue? ¿Es suficiente con postular valores lógicos adicionales? ¿No implica eso una linealidad falsa, no lo suficientemente compleja: de dos, tres, cuatro, $n$ valores? (p. 61-62). 
que asegura Naomi Schor: "[...] the body qua body has been posited as integral and fully sensate"7 (1999, p. 84).

La oposición fundamental a la forma binaria de la lógica clásica y su primacía metodológica conecta la cibernética del segundo orden con el proyecto de Michel Foucault en Las palabras y las cosas (1966). La investigación arqueológica que realiza muestra dos grandes discontinuidades en la episteme de la cultura occidental: la que inaugura la época clásica -hacia mediados del siglo XVII- y la que, a principios del siglo XIX, señala el umbral de la modernidad. La diferencia clave entre los dos momentos, según constata Foucault, no se debe a los progresos de la razón. Se trata de un cambio profundo en "el orden a partir del cual pensamos" que revela una transformación total del "sistema de positividades" - de lo que se consideran como cosas evidentes y comprobables en un momento histórico determinado. En este sentido, la fuerte impresión de un movimiento ininterrumpido de la ratio europea, desde el Renacimiento hasta nuestros días - la continuidad a nivel de las ideas-es un efecto superficial. Como asegura, a partir del siglo XIX, ya no es posible una coherencia completa entre la teoría de la representación y las del lenguaje:

[...] desaparece la teoría de la representación como fundamento general de todos los órdenes posibles; se desvanece el lenguaje en cuanto tabla espontánea y cuadrícula primera de las cosas, como enlace indispensable entre la representación y los seres; una historicidad profunda penetra en el corazón de las cosas, las aísla y las define en su coherencia propia, les impone aquellas formas del orden implícitas en la continuidad del tiempo; el análisis de los cambios y de la moneda cede su lugar al estudio de la producción, el del organismo se adelanta a la investigación de los caracteres taxonómicos; pero, sobre todo, el lenguaje pierde su lugar de privilegio y se convierte, a su vez, en una figura de la historia coherente con la densidad de su pasado. Sin embargo, a medida que las cosas se enrollan sobre sí mismas, pidiendo solamente a su devenir el principio de su inteligibilidad y abandonando el espacio de la representación, el hombre, a su vez, entra, por vez primera, en el campo del saber occidental. (2010, p. 16, énfasis nuestro)

La investigación de Foucault, contemporánea a la escritura de Clarice Lispector -Laços de família, 1960; Água viva, 1973- dialoga con la propuesta narrativa de la escritora, una vez que la posición ambigua hacia la palabra literaria fisura la representación del lenguaje como fundamento de todos los órdenes posibles. Además, como se verifica en "Amor", es notoria la naturalización de la paradoja, que expone la permeabilidad de los sistemas de distinción. La angustia frente a la impotencia de lo verbal estimula, en ambos escritos de Lispector, un apelo insistente a otras formas de expresión. La

7 "O corpo em quanto corpo se propóe como integral e completamente sensível". 
noción de la escritura como un desabrochar del escritor conecta la búsqueda metalingüística con la pregunta sobre la subjetividad humana, aspecto que gana fuerza en los personajes inmersos en una profunda auto-reflexión. Todos estos cambios del lenguaje, que forjan una nueva manera de "decir esto", también anuncian el potencial transformador de la literatura al trastocar radicalmente la idea de un acto de lectura y anticipar sus posibles consecuencias, más allá del texto literario.

Como declara la narradora de Água viva, la desarmonía armoniosa en la música, en la escritura y en la pintura alude al descubrimiento de que no es preciso un orden para vivir y que no hay patrón a seguir:

Agora estou com medo. Porque vou te dizer uma coisa. Espero que o medo passe. Passou. É o seguinte: a dissonância me é harmoniosa. A melodia por vezes me cansa. E também o chamado "leit-motit". Quero na música e no que te escrevo e no que pinto, quero traços geométricos que se cruzam no ar e formam uma desarmonia que eu entendo. É puro it. Meu ser se embebe todo e levemente se embriaga. Isto que estou te escrevendo é muito importante. E eu trabalho quando durmo: porque é então que me movo no mistério. (1998a, p. 46, énfasis nuestro)

Negar la melodía y el tema es afirmar el "puro it". No obstante, la búsqueda de un arte abstracto convive con la contradicción de reivindicar la palabra. Además, por momentos esta se convierte en la mejor forma de manifestar la intimidad de uno mismo y del otro:

Escrevo-te toda inteira e sinto um sabor em ser e o sabor-a-ti é abstrato como o instante. é também com o corpo todo que pinto os meus quadros e na tela fixo o incorpóreo, eu corpo-a-corpo comigo mesma. Não se compreende música: ouve-se. Ouve-me entấo com teu corpo inteiro. Quando vieres a me ler perguntarás por que não me restrinjo à pintura e às minhas exposições, já que escrevo tosco e sem ordem. É que agora sinto necessidade de palavras -e é novo para mim o que escrevo porque minha verdadeira palavra foi até agora intocada. A palavra é a minha quarta dimensão. (p. 3, énfasis nuestro)

Como se revela, la obra de Clarice Lispector, lejos de negar el valor del lenguaje verbal, exhibe enfáticamente su estado de crisis. La necesidad de la palabra nueva, intocada -como cuarta dimensión- establece analogía con la taxonomía inusual de Borges. Incita la misma pregunta sobre "lo que es imposible pensar y de que imposibilidad se trata", que plantea Foucault. En este marco, en Água viva, no sólo se pretende que la palabra contradiga su función representativa emanando un sabor a ser y un sabor a ti, gracias a la posibilidad de escribir y escuchar cuerpo-a-cuerpo. La cuestión también, como en Borges, es proponer un espacio común en ruinas. Sugerir el no-lugar 
del lenguaje como único territorio posible pero que, inevitablemente, se despliega hacia lo impensable (FOUCAULT, 2010, p. 10-11). En la escritura de Lispector, el límite de la palabra se reitera y se sobrepone mediante dos movimientos: el cuestionamiento de la imposibilidad de pensar, decir y expresar "esto" y la invocación del cuerpo como lenguaje. Es abstracto, como bien dice la escritora, pero, en la búsqueda del it, -como lo más crudo y esencial de la vida-escribirse entera es la única forma de comunicarse con el "tú", que debe escuchar, en la suspensión del instante, con el cuerpo entero. Como es posible experimentar, la respuesta a lo que es imposible pensar y a la imposibilidad misma no se limitará a una reflexión metalingüística. En su escritura, la puesta en escena del cuerpo y la convivencia sinestésica asumen una importancia fundamental.

Observemos "Amor" el segundo cuento de Laços de família ${ }^{8}$. La primera parte consiste en la exposición de la vida de Ana, una madre de familia que "plantara as sementes que tinha na mão, não outras, mas essas apenas" (1998b, p. 1). Ana cayó tortuosamente en un destino de mujer, con la sorpresa de caber en él como si lo hubiese inventado. Emerge de su extrańa juventud anterior, que parece enfermedad de vida, para descubrir que "sem a felicidade se vivia". En medio de una legión de personas (invisibles) que viven como quien trabaja, acepta la vida comprensible de un adulto, renunciando a la exaltación perturbada que tantas veces se confundía con una felicidad insoportable: "assim ela quisera e escolhera". Sin embargo, el deseo de tornar los días realizados y bellos y la impresión de "que tudo era passível de aperfeiçoamento"/"que a vida podia ser feita pela mão do homem" se ven diariamente amenazados por la llegada de una cierta hora de la tarde en que los árboles (que ella misma plantara) se ríen de su intento. Mirando la casa vacía y los muebles que ya no le necesitan, se aprieta su corazón con espanto. Casada con un hombre verdadero y madre de hijos igualmente verdaderos y suculentos, Ana sabe que pertenece obscuramente a las raíces negras y suaves del mundo. Sentada en un tranvía con el gesto de gran aceptación que reviste su rostro de mujer se termina la hora estable de Ana. Mira un hombre ciego inmóvil en el paradero. Confirma que es un hombre ciego mascando chicles y empieza a sentir que algo intranquilo estaba en curso. Ana pretende pensar pero el corazón empieza a latir violento y de espacio. Conmovida por los particulares movimientos de su órgano vital, se produce el cambio de mirada:

Inclinada, olhava o cego profundamente, como se olha o que não nos vê. Ele mastigava goma na escuridão. Sem sofrimento, com os olhos abertos. O movimento da mastigação fazia-o parecer sorrir e de repente deixar de sorrir,

8 LISPECTOR, Clarice. Laços de familia. Rio de Janeiro: Rocco, 1998. Todas las citas se refieren a esta edición. 
sorrir e deixar de sorrir -como se ele a tivesse insultado, Ana olhava-o. E quem a visse teria a impressão de uma mulher com ódio. Mas continuava a olhálo, cada vez mais inclinada- o bonde deu uma arrancada súbita jogando-a desprevenida para trás, o pesado saco de tricô despencou-se do colo, ruiu no chão - Ana deu um grito, o condutor deu ordem de parada antes de saber do que se tratava- o bonde estacou, os passageiros olharam assustados. (1998b, p. 14 , énfasis nuestro)

En este fragmento, llama la atención los varios "olhares" que componen el cuadro. La mirada inicial de Ana, a pesar de profunda, demarca una clara distancia entre observador y observado. Es una mirada fija, que confirma la exterioridad del espectador de la escena. En este sentido, su actitud alude a los movimientos del ocularcentrismo identificados por Martin Jay, en Ojos abatidos. Al establecer correspondencias entre la convención de la perspectiva en el arte europeo, la desnarrativización de lo ocular, la revolución científica y la separación del momento participativo de la "theoria", Jay asegura que el desenmarańamiento de lo figurativo respecto a su tarea textual es determinante para la generalizada "mecanización de la imagen del mundo". Este conjunto de factores, ligados a una transformación de época, definen el salto a una nueva lectura del mundo como un objeto observable pero carente de significado. En el arte, la invención o redescubrimiento de la perspectiva impone una sobrevaloración de las reglas y procedimientos frente al tema representado. El espacio, más que los objetos que había en él, cobra una importancia creciente. De acuerdo con Jay, lo más impresionante de este proceso es la sintonía que instituye con el nuevo orden científico: "En ambos casos el espacio se vio desprovisto de su significado sustantivo para convertirse en un sistema ordenado y uniforme de coordenadas lineales abstractas" (2007, p. 46-51) ${ }^{9}$. La mecanización de la imagen del mundo - tan esencial para la ciencia modernatambién proscribe la narración "del método cognitivo que producía la "verdad" sobre la realidad externa" (48). Asimismo, es notoria la coherencia entre la visión de mundo ocularcentrista y el nuevo orden económico en expansión: "Fue este espacio isotrópico, infinito y uniforme, el que marcó la diferencia entre la visión dominante del mundo moderno y sus diversas predecesoras, una noción de espacio compatible no sólo con la ciencia moderna, sino también, se ha dicho, con el sistema económico emergente al que nosotros damos el nombre de capitalismo" (51). Considerando esta perspectiva, las características de un mundo burgués y ocularcéntrico, en que el espectador está en el centro de la visión, están en perfecta consonancia con la escena que aparece en "Amor". Observemos otra vez: Ana mira el ciego desde una

9 Como afirma Jay en Ojos abatidos, sus conclusiones en este apartado dialogan con las consideraciones de Foucault en Las palabras y las cosas sobre el emblema del orden epistemológico moderno (2007, p. 46). 
considerable distancia. Insiste en la mirada y deduce una oscuridad. Insiste en la mirada y sigue sin entender porque el ciego no parece sufrir, sino que transmite una insultante sonrisa alternada. La actitud del ciego le intriga, produce una impresión de odio y, finalmente, estimula el grito. ¿Qué despierta la intranquilidad de Ana? Su gesto sugiere la incapacidad de mirar-entender la diferencia. Más adelante, esta imposibilidad se confirma en la exposición de que la estabilidad de su destino de mujer - apoyada en el encierro del hogar y de la familia - se sustenta en un sistema de oposiciones:

Ela apaziguara táo bem a vida, cuidara tanto para que esta não explodisse. Mantinha tudo em serena compreensáo, separava uma pessoa das outras, as roupas eram claramente feitas para serem usadas e podia-se escolher pelo jornal ou filme da noite - tudo feito de um modo que um dia se seguisse ao outro. E um cego mascando goma despedaçava tudo isso. Eatravés da piedade aparecia a Ana uma vida cheia de náusea doce, até a boca. (p. 15, énfasis nuestro)

Todo se despedazaba porque Ana no entendía la aparición de un ciego con ojos abiertos y aparentemente feliz. No obstante, su incomprensión inicial - la mirada fría y distante - se transforma desde la puesta en escena de su cuerpo a través del grito. Surge una expresión de rostro que hacía mucho no usaba. Como metáfora de su pequeño mundo hogareño, se rompen los huevos. El tranvía arranca, el ciego queda para tras, pero el mal ya estaba hecho. Porque, además, empieza a sentir una piedad sofocante. En este momento, se anuncia la pérdida de sentido de lo anterior y la llegada de lo nuevo: "E como uma estranha música, o mundo recomeçava ao redor. O mal estava feito" (14). La alusión al lenguaje musical recuerda la disonancia armoniosa - la desarmonía que yo entiendo - reinvidicada en Água viva y nos transfiere a la lectura de Paul de Man sobre la cercanía en Jean-Jacques Rousseau entre el lenguaje del habla y la estructura musical. Sobre esta idea, de Man asegura, en Visión y ceguera. Ensayos sobre la retórica de la crítica contemporánea, que las dos formas de comunicación se apoyan en un sistema diacrónico de relaciones. De acuerdo con su punto de vista, la secuencia sucesiva de un relato o narración se opone al sincronismo desorientador de la percepción visual que crea la falsa ilusión de presencia (1991, p. 147). La imbricación entre los dos lenguajes (del habla y musical), tomado como un recurso dramático, también puede ser un gesto antiocularcéntrico: "Se favorecen las estructuras diacrónicas como la música, la melodía, o la alegoría, sobre las estructuras seudo sincrónicas como la pintura, la armonía, o la mimesis porque éstas hacían creer falsamente en la estabilidad del sentido que no existe" (148). Finalmente, de Man asegura que todo lenguaje secuencial es lenguaje dramático, narrativo. Y la pasión en Rousseau, "es precisamente la manifestación de una voluntad que existe independiente de un significado o intención específica y que, por lo tanto, jamás puede hacerse remontar 
a una causa u origen" (147). Siendo así, el lenguaje musical cuenta con el privilegio de no tener que significar nada. No obstante, esta afirmación no debe ser considerada en un sentido literalmente reduccionista. Retomando las conclusiones de Luhmann: en toda comunicación, como operación que ejecuta las observaciones, siempre se distingue e indica algo, independientemente del grado de latencia (1998, p. 66).

Observemos, en "Amor", cuál es el lado de la vida cotidiana que se elige mostrar después que la protagonista se da cuenta (o recuerda) de que sí, en el mundo existen ciegos:

A piedade a sufocava, Ana respirava pesadamente. Mesmo as coisas que existiam antes do acontecimento estavam agora de sobreaviso, tinham um ar mais hostil, perecivel... O mundo se tornara de novo um mal-estar. Vários anos ruíam, as gemas amarelas escorriam. Expulsa de seus próprios dias, parecia-lhe que as pessoas na rua eram periclitantes, que se mantinham por um mínimo equilíbrio à tona da escuridão - e por um momento a falta de sentido deixava - as tão livres que elas não sabiam para onde ir. Perceber uma ausência de lei foi tão súbito que Ana se agarrou ao banco da frente, como se pudesse cair do bonde, como se as coisas pudessem ser revertidas com a mesma calma com que não o eram. (1998b, p. 14, énfasis nuestro)

Durante esta inflexión del cuento, la percepción de un mundo perecible confirma todo lo que viene siendo indicado (oblicuamente) sobre la vida de Ana. Porque, su intento inicial de realizar días maravillosos y bellos no sólo está marcado por la ironía de la narración, sino también, carece totalmente de sentido. Recordemos el suspiro de media satisfacción; la apariencia armoniosa de una vida hecha por las manos del hombre; y, finalmente, la abolición de la felicidad para caber en un destino de mujer. Por otro lado, en el nuevo mundo anunciado por la música, Ana se encuentra con la moral del jardín, con su impersonalidad soberbia. Aquí, el trabajo secreto de la naturaleza le despierta, paradójicamente, fascinación y asco. El jardín revela la parte más fina del mundo, dotada de una crudeza tranquila y de una riqueza casi podrida. Desde este momento, intuimos que esta vida llena de nausea dulce, de piedad y de fe es poderosa porque produce susto, asco, estremecimiento y, luego, un profundo horror (insistente) en Ana. De alguna manera adivinamos que, a despecho de la impresión de debilidad y de una vida periclitante por parte de la protagonista, este es el lado fuerte del mundo. Es lo que la salva de su alienación inicial y final. No obstante, en sintonía con un uso ambiguo de la palabra, el procedimiento narrativo no se resume a una oposición entre el hogar burgués de Ana y la proliferación vital del jardín. El tono y la adjetivación diseminan el doble sentido. Siendo así, las poderosas descripciones se sustentan en la "armonía de los contrarios". Además, en la narración de este nuevo 
mundo, no es suficiente proponer imágenes a través de las palabras. En la experiencia de Ana se evocan todos los sentidos y la sinestesia aparece como convivencia, compensación y equilibro entre los mismos. Su visión guiada por el ciego conduce sus primeros pasos en un mundo: "faiscante, sombrio, onde vitórias-régias boiavam mostruosas" (1998b, p. 16). Su percepción de los colores también aparece alterada: "As pequeñas flores espalhadas na relva não the pareciam amarelas ou rosadas, mas cor de mau ouro e escarlates" (16). El olfato, como la vista, combina sensaciones opuestas: "A decomposição era profunda, perfumada..." (16). La percepción de los sentidos, a veces simultánea, es sin duda complementaria. El (con)tacto con la tierra reúne las dos condiciones: "Sob os pés a terra estaba fofa, Ana aspirava-a com delícia" (16). Y es el vago sentimiento de asco que aproxima a Ana a "la verdad" y dota su experiencia del más profundo equilibrio.

Los animales casi no aparecen. Son nombrados aves e insectos y, a parte de los otros, un gato. Todos, en su movimiento suave e íntimo, acompañan la protagonista, como la levedad de la "enjambre de insectos" que le ayuda a suportar las pesadas cosas que recibe. Esta actitud hacia las plantas y los animales remite a la idea de convivencia a que se refiere Florencia Garramuño. En "Región compartida. Pliegues de lo animal-humano" la investigadora argentina defiende que, en la escritura de Clarice Lispector, la convivencia entre animales y humanos no supone ni necesita semejanzas sino que se basta a sí misma con la compartida exposición a las fuerzas de la vida. Sobre la escritura específicamente, es como si se abriera, desde esa convivencia con lo animal, a la narración de formas diferenciadas, múltiples y heterogéneas de vida. Además, como también identifica Garramuño, se desintegra cualquier jerarquía entre lo humano, animal u orgánico (2011, p. 3). Sobre el mismo aspecto, es posible indicar que la escritura de Lispector invierte el movimiento de la muerte animal como mecanismo constitutivo y definitorio de lo humano que despliega una idea de superioridad ontológica - aspecto analizado por Gabriel Giorgi en "La vida impropia. Historias de mataderos". En "Amor", si se percibe una exposición de la excepción humana es para mostrar la limitación normativa que imposibilita la convivencia con lo diferente: el ciego y las otras criaturas vivientes. En Água viva también aparece una contraposición radical a la idea de supremacía humana: "Às vezes eletrizo-me ao ver bicho. Estou agora ouvindo o grito ancestral dentro de mim: parece que não sei quem é mais a criatura, se eu ou o bicho. E confundo-me toda. Fico ao que parece com medo de encarar instintos abafados que diante do bicho sou obrigada a assumir" (1998a, p. 33-34, énfasis de la autora). Desprendidas de una visualidad que categoriza, las protagonistas de ambos escritos sienten - cada una a su modo - la pulsión animal. El miedo a aceptarla está determinado por el "sentido de medida”. Como indica Clarice Lispector en la crónica de 1968 que nos 
sirve de epígrafe, esta convención es tan poderosa que también de-limita el mundo de los sentimientos.

Queda por decir, en Laços de familia el cuestionamiento de un orden convencional de las cosas no se resume a los movimientos del lenguaje. En "Amor", se expone con sarcasmo la vida burguesa de Ana y, aunque no se generen dicotomías categóricas, esta realidad de aparente estabilidad se diferencia radicalmente del des-orden del jardín. Sobre la particular forma de oposición que opera en el cuento, vale la pena destacar dos importantes inversiones que se realizan durante la evaluación de los dos mundos. Por un lado, luego de la inmersión de Ana en el jardín, marcada por la sinestesia y por los sentimientos contradictorios, se concluye sobre su experimentación: "O Jardim era tão bonito que ela teve medo do inferno" (1998b, p. 16). Por otro, cuando regresa a casa después de recordar sus hijos - y su sentimiento de culpa respecto a ellos - Ana percibe que fue atingida por el demonio de la fe. Estas asociaciones trastruecan explícitamente el valor semántico de los términos vinculados al cristianismo. Se suma a este gesto, la impresión de Ana de que la vida sana que llevaba era moralmente loca. Porque el aspecto armónico de la sala cuadrada y de las ventanas limpias viene acompañado de la abolición de la felicidad, de la ausencia de piedad y de la injusticia del hambre. La contención de la familia se reafirma en el final del cuento: "Depois do jantar, enfim, a primeira brisa mais fresca entrou pelas janelas. Eles rodeavam a mesa, a família. Cansados do dia, felizes em não discordar, tão dispostos a não ver defeitos. Riam-se de tudo, com o coração bom e humano" (19, énfasis nuestro). La actuación de la familia de Ana remite a la búsqueda de "unidad de lo distinguido" que, como explica Luhmann, se sustenta en el castigo de la paradoja y de su despliegue: la búsqueda de consideraciones y formas que justifiquen nuevas elecciones e indicaciones (1998, p. 69). Al mismo tiempo, si como premisa de operaciones ulteriores todas las indicaciones son parcialmente ciegas en sus propósitos, en "Amor" lo sustancial de establecer una diferenciación entre los dos mundos y formas de percepción es indicar que, en el jardín, se asume la mirada sesgada, desinteresada de un punto de vista dominante y unísono. Esta disonancia fundamental, que implica la valoración del lado inaprensible de la vida, se conecta con el reconocimiento epistemológico de la latencia que, desde la cibernética del segundo orden, incita la siguiente inquietud: " ¿El conocimiento en el sentido de construcción se basa en que sólo funciona porque el sistema cognoscente está cerrado operativamente, es decir, porque no puede mantener un contacto operativo con el mundo circundante; y porque por esa razón, para todo lo que construye depende de la propia distinción entre autorreferencia y referencia externa?" (p. 69-70, énfasis del autor). En contraste con esta segregación entre teoría y práctica, la correspondencia entre literatura y vida es un punto neurálgico en la escritura de Clarice Lispector. 
El cambio de la mirada de Ana implica una transformación total de la realidad que percibe. Luego de considerar una tranquila reversión de las cosas, viene la crisis marcada por el "prazer intenso com que as olhava agora":

O calor se tornara mais abafado, tudo tinha ganho uma força e vozes mais altas. Na Rua Voluntários da Pátria parecia prestes a rebentar uma revolução, as grades dos esgotos estavam secas, o ar empoeirado. Um cego mascando chicles mergulhara o mundo em escura sofreguidão. Em cada pessoa forte havia a ausência de piedade pelo cego e as pessoas assustavam-na com o vigor que possuíam. Junto dela havia uma senhora de azul, com um rosto. Desviou o olhar, depressa. Na calçada, uma mulher deu um empurrão no filho! Dois namorados entrelaçavam os dedos sorrindo... E o cego? Ana caíra numa bondade extremamente dolorosa. (1998b, p. 14-15)

La intensidad que acomete la mirada de Ana es clave e impulsa su nuevo experimentar. Ella está revertida y su hipersensibilidad -su sufrimiento espantado-evoca la inminencia de una revolución. Su corazón late de miedo, ya no puede reconocer los alrededores y todo le provoca susto. Mientras tanto, la vida que descubre sigue pulsando y un viento misterioso le ronda el rostro. La imbricación entre las transformaciones de la vida interior y exterior de la protagonista y las fluctuaciones de la palabra y tonalidades de la narración incluye otro elemento. Al llegar al "Jardim Botânico" Ana percibe la amplitud y el silencio del espacio que le tranquiliza y regula su respiración: "Ela adormecia dentro de si" (15). Entre los ruidos serenos, el olor de los árboles y las pequeñas sorpresas de las lianas, ella parece encontrar un "medio sueño" en este ambiente: "Tudo era estranho, suave demais, grande demais" (16). Sintiendo malestar, entra en este espacio como en una emboscada. En este momento, la vacilación sobre la materialidad de su experiencia despierta nuevas formas de percepción: "Ao mesmo tempo que imaginário - era um mundo de se comer com os dentes, um mundo de volumosas dálias e tulipas. Os troncos eram percorridos por parasitas folhudas, o abraço era macio, colado. Como a repulsa que precedesse uma entrega - era fascinante, a mulher tinha nojo, e era fascinante" (p. 16, énfasis nuestro). Es imposible precisar lo que se sugiere con esta idea. Sin embargo, la verosimilitud es irrelevante. Porque el mundo del jardín es una realidad, independiente de su grado de invención. En todos los sentidos, esta experiencia potente e imprecisa amplía las formas de percepción, contacto y convivencia de Ana con el mundo. En "Amor", la crudeza tranquila del ambiente natural resguarda su latencia. Fascinante y asqueroso, el jardín también invita (oblicuamente) a "escuchar" con el cuerpo entero.

"Estou sendo antimelódica. Comprazo-me com a harmonia difícil dos ásperos contrários. Para onde vou? e a resposta é: vou" (1998a, p. 19) -medita 
la narradora de Água viva. Al mismo tiempo, "Amor" sigue proliferando la paradoja: "O mundo era tão rico que apodrecia" (1998b, p. 16). Sin embargo, en este ir sin saber el destino, se revelan las dificultades del camino: "Quem me acompanha que me acompanhe: a caminhada é longa, é sofrida mas é vivida. Porque agora te falo a sério: não estou brincando com palavras. Encarno-me nas frases voluptuosas e ininteligíveis que se enovelam para além das palavras" (1998a, p.13). Para Clarice Lispector, la escritura es, antes de todo, cuestión de vida. Como indica en este fragmento de Água viva, hablar en serio con la palabra estimula una encarnación que, aunque inexacta, se despliega hacia un más allá del lenguaje. La literatura como construcción de mundo, la necesidad de una realidad inventada, es una forma de liberación - expresiva y vital - como indicamos al principio. Es la fuga de Ana hacia el jardín. Y la lucha de la narradora de Água viva por conquistar su libertad de sensaciones y pensamientos sin ningún fin utilitario. En "Amor", como en Água viva, también aparece la pregunta sobre las consecuencias de elegir a contracorriente de lo convencional: "O que faria se seguisse o chamado do cego? Iria sozinha...” (1998b, p. 17). En los términos de Gilles Deleuze, la salud como literatura consiste en inventar un pueblo que falta. En correspondencia con esta posición, la soledad que asume Lispector se hace más comprensible: "Precisamente, no es un pueblo llamado a dominar el mundo, sino un pueblo menor, eternamente menor, presa de un devenir-revolucionario. Tal vez solo exista en los átomos del escritor, pueblo bastardo, inferior, dominado, en perpetuo devenir, siempre inacabado" (1996, p. 15). En "Amor", esta vida que "causa escalofríos" es un mal, un vago sentimiento de asco, pero también, una aproximación a la verdad. La percepción del trabajo secreto de la naturaleza que Ana ya no puede evitar - le presenta una vida silenciosa, lenta, insistente que le hace maldecir: "Horror, horror". La revelación -que ella más adivina que siente- está muy lejos de delinear una realidad en que no se disiente o no se ven los defectos, como en la familia. Es una descripción de mundo libre de cualquier pulsión hegemónica. Se experimenta oblicuamente y con un alto grado de latencia. Tanto en "Amor" como en Água viva la paradoja es inmanente a la narración y la incoherencia es inevitable. En este sentido, es posible establecer un nuevo paralelo con el discurso antiocularcéntrico que -de acuerdo con Martin Jay- debe ser entendido como, "[...] un tejido asistemático, en ocasiones internamente contradictorio, de aseveraciones, asociaciones y metáforas que nunca llegan a cohesionar de manera rigurosa" (2007, p. 21). Desprendida de la búsqueda de resultados, la escritura de Clarice Lispector parece asumir una responsabilidad total frente al lenguaje, rehusándose a entender las palabras como vehículos indiferentes: sin vida, sin personalidad y sin historia. Los diversos lenguajes, expandidos hacia nuevas formas de vivir-sentir, invitan el receptor a experimentar con el cuerpo entero. 
Este desafío también inspira un acto de lectura que sobrepasa el desabrochar individual y cumple con un devenir-revolucionario al propagar, desde "lo menor", nuevos y más amplios mundos. Arriesgarse a esta "grandeza" también implica convivir, íntimamente, con otras formas de vida.

\section{REFERENCIAS BIBLIOGRÁFICAS}

BENJAMIN, Walter. Sobre algunos temas Baudelaire. In: Iluminaciones II. Baudelaire. Un poeta en el esplendor del capitalismo. Prólogo y Traducción de Jesús Aguirre. Madrid: Taurus, 1972, p. 123-170

DE MAN, Paul. La retórica de la ceguera: Jacques Derrida y la lectura de Rousseau. In: Visión y Ceguera. Ensayos sobre la retórica de la crítica contemporánea. San Juan: Editorial de la Universidad de Puerto Rico, 1991, p.115-157.

DELEUZE, Gilles. La literatura y la vida. In: Crítica y clínica. Barcelona: Anagrama, 1996, p. 11-18

FOUCAULT, Michel. Las palabras y las cosas. Una arqueología de las ciencias humanas. México: Siglo XXI, 2010.

GARRAMUÑO, Florencia. Región compartida. Pliegues de lo animal-humano. Boletin 16 del Centro de Estudios de Teoría y Crítica Literaria, 2011, p. 1-14. Disponible en <http://www.celarg.org/int/arch_publi/garramu_o_animalidad. pdf>.

GIORGI, Gabriel. La vida impropia. Historias de mataderos. Boletín 16 del Centro de Estudios de Teoría y Crítica Literaria, 2011, p. 1-14. Disponible en <http:// www.celarg.org/int/arch_publi/giorgi_animalidad.pdf>.

JAY, Martin. Ojos abatidos. La denigración de la visión en el pensamiento francés del siglo XX. Madrid: Akal, 2007.

LISPECTOR, Clarice. Água viva. Rio de Janeiro: Rocco, 1998a.

LISPECTOR, Clarice. Laços de familia. Rio de Janeiro: Rocco, 1998b.

LISPECTOR, Clarice. Entrevista por Julio Lerner. Panorama. Tv Cultura, 1977. Web. 30 de junio de 2014. Disponible en <http://www.youtube.com/ watch?v=TbZriv5THpA\&list=PL2A2BB5B605E3FB0A\&index=5>.

LUHMANN, Niklas. ¿Cómo se pueden observar estructuras latentes? In: Watzlawick, Paul y Krieg, Peter. In: El ojo del observador: contribuciones al constructivismo. Barcelona: Gedisa, 1998, p.60-72. 
PEDRÓN, Eleonora Cróquer. Clarice Lispector: una lectura a partir del desconcierto. Ficciones del contacto. Fisuras de la representación: los márgenes de una escritura del margen. Revista de Investigaciones literarias, año 3, n. 6, Caracas, 1995, p. 211-229.

SCHOR, Naomi. Blindness as Metaphor. differences: A jornal of Feminist Cultural Studies, 11(2), 1999, p. 76-105.

Renata Pontes está concluindo um doutorado em literatura pela Pontificia Universidad Católica de Chile. Tem mestrado em Literaturas Espanhola e Latino-americana pela Universidad de Buenos Aires. Atualmente, integra o Doutorado em Espanhol da Temple University, onde também ensina espanhol como "teaching assistant". E-mail: renata.pontes@temple.edu; rpontes@uc.cl 